\title{
Current situation and future prospects for beef production in South Korea - A review
}

\author{
Ki Yong Chung ${ }^{1, a_{1} *}$, Seung Hwan Lee ${ }^{2, a}$, Soo Hyun Cho ${ }^{3}$, Eung Gi Kwon', and Jun Heon Lee ${ }^{2}$
}

* Corresponding Author: Ki Yong Chung Tel: +82-33-330-0613, Fax: +82-33-330-0660,

E-mail: cky95@korea.kr

${ }^{1}$ Hanwoo Research Institute, National Institute of Animal Science, RDA, Pyeongchang 25340, Korea 2 Division of Animal \& Daily Science, Chungnam National University, Daejeon 34148, Korea

3 Division of Animal Production, National Institute of

Animal Science, RDA, Wanju 55365, Korea

${ }^{a}$ These authors contributed equally to this work.

\section{ORCID}

Ki Yong Chung

https://orcid.org/0000-0003-0957-875X Seung Hwan Lee

https://orcid.org/0000-0003-1508-4887

Soo Hyun Cho

https://orcid.org/0000-0002-8073-8771

Eung Gi Kwon

https://orcid.org/0000-0002-7894-7558

Jun Heon Lee

https://orcid.org/0000-0003-3996-9209

Submitted Mar 7, 2018; Revised Apr 10, 2018; Accepted May 7, 2018

\begin{abstract}
Hanwoo cattle are an important food source in Korea and their supply can have a major impact on meat availability for Korean consumers. The Hanwoo population was 1.8 million head in 2005 and gradually increased to 2.6 million in 2015. Per capita beef consumption has also increased, to $11.6 \mathrm{~kg}$ per year in 2015 , and is expected to continue to increase. Because intramuscular fat percentage is a critical contributor to meat quality, Hanwoo cattle are fed a high-energy corn-based diet for long fattening periods. Long fed diet causes significant alterations in fat percentage in the loin muscle and other areas of the carcass. However, these long feeding periods increase feeding costs and beef prices. Recently, there has been increased Korean consumer demand for lean beef which has less fat, but is tender and priced more reasonably. These consumer demands on the Korean beef industry are driving differing beef production systems and also changes to the beef grading methodology. Korean government has made a significant investment to select bulls with favorable production traits using progeny testing. Progeny tested bull semen has been disseminated to all Hanwoo farmers. A beef traceability system has been employed for all cattle breeds in Korea since 2009. Hanwoo cattle are ear-marked with a 12-digit identification number from birth to slaughter. This number allows traceability of the management history of individual cattle, and also provides information to consumers. Traceability including management information such as herd, farm, year of birth, and carcass data can determine estimated breeding values of Hanwoo. For a sustainable Hanwoo industry, research scientists in Korea have attempted to develop feeds for efficient fattening periods and precision feeding systems based on genetic information for Hanwoo cattle. These initiatives aim to Korean consumer demands for beef and provide more precision management in beef production in Korea.
\end{abstract}

Keywords: Hanwoo; Carcass Grading System; Precision Management; Progeny Tested Bull

\section{INTRODUCTION}

The livestock industry accounts for almost $40 \%$ of total agricultural production in South Korea [1]. Moreover, beef production ranks second (30\% of meat produced) among sources of meat production in South Korea (Figure 1). The number of South Korean households raising Hanwoo cattle has been decreasing for decades (Figure 2). According to the Hanwoo traceability system of the Korean Institute for Animal Products Quality Evaluation (KAPE), the number of Hanwoo cattle was 1.8 million in 2005, but had increased to 2.6 million in 2017. However, the number of households rearing Hanwoo cattle in 2010 was 172,000 and decreased to 84,000 in 2017. These trends have led to an increase in the number of Hanwoo per farmer (Table 1) with the average number of Hanwoo cattle per household being 29.6 in 2017 [1]. Moreover, there has been an increase in the amount of Hanwoo beef produced in larger-scale feedlot systems that rear over 100 head [1]. Furthermore, the average consumption of Hanwoo beef has increased from 6.7 to $11.5 \mathrm{~kg}$ per person during recent decades 

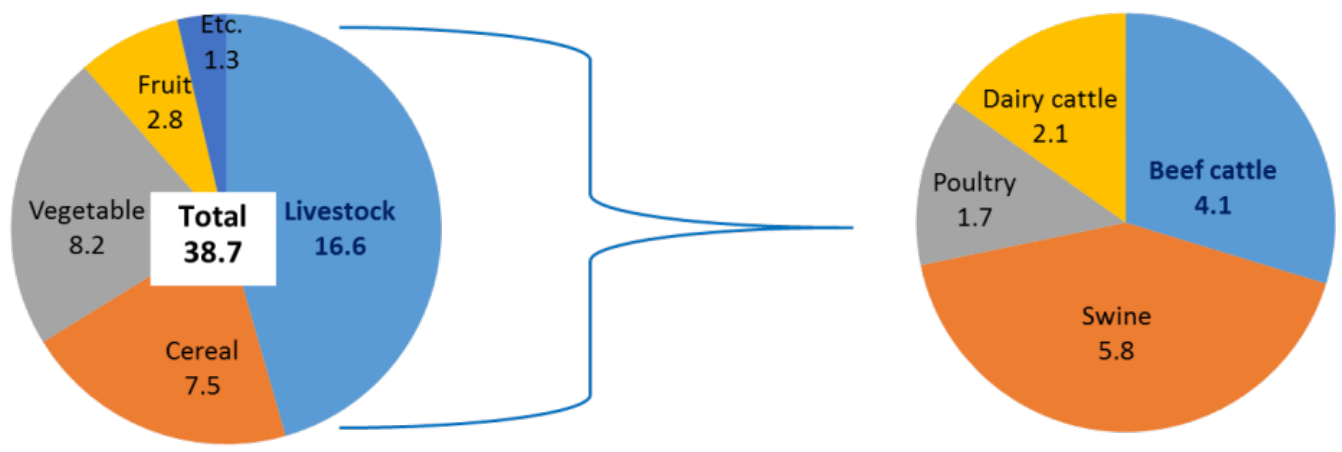

Unit : billion US \$, 1 US\$ equivalent to 1,170 Korean)

Figure 1. Annual agricultural production of South Korea [1].

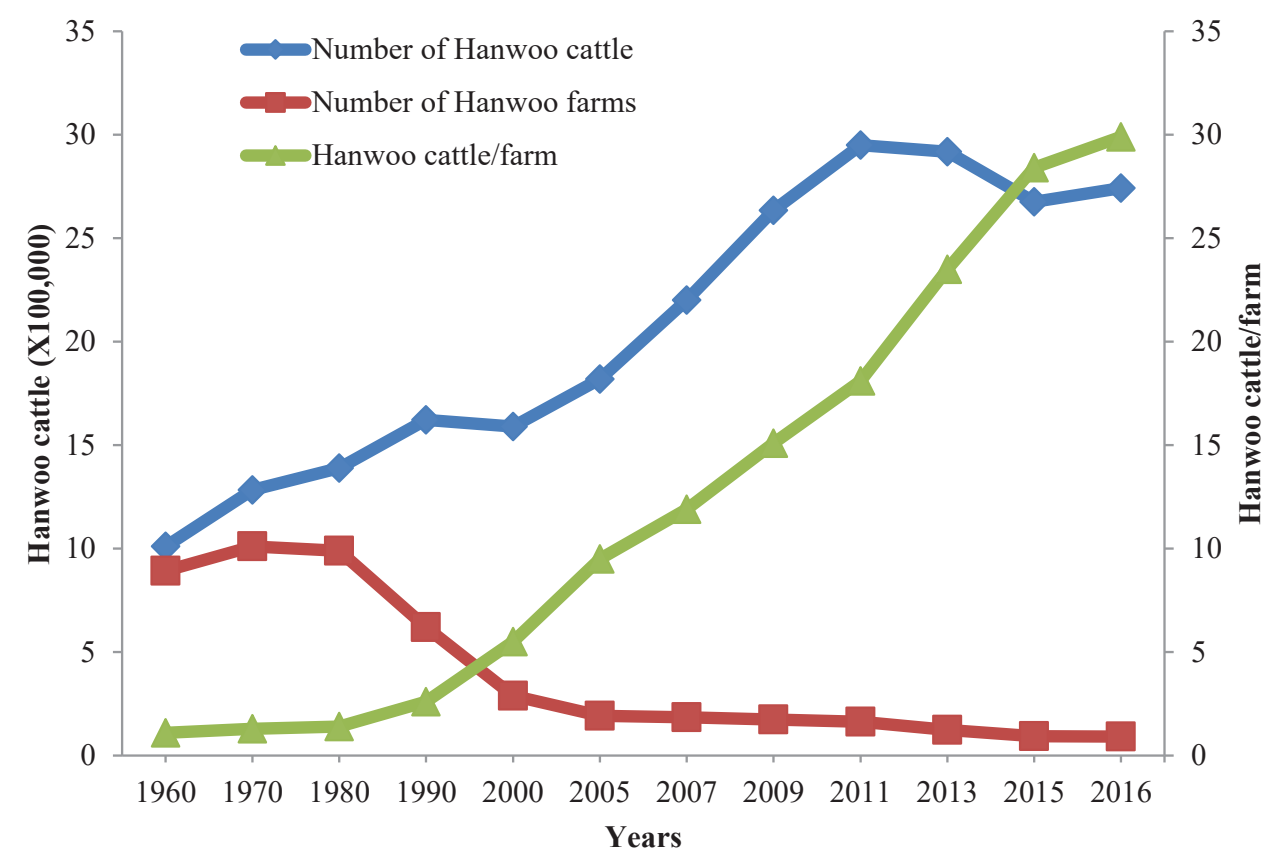

Figure 2. Changes in the population of Hanwoo cattle and number of Hanwoo farms and their size in South Korea [29].

(Figure 3). The Hanwoo industry in South Korea has increased not only in cattle numbers, but also in the performance of the beef cattle. To better understand the Hanwoo industry in South Korea, this review evaluates the development of breeding and feeding systems for Hanwoo cattle.

Table 1. Number of farms and size of livestock populations by species [29]

\begin{tabular}{lccc}
\hline Species & $\begin{array}{c}\text { Number } \\
\text { of farms }\end{array}$ & $\begin{array}{c}\text { Total size } \\
(\mathbf{1 , 0 0 0} \text { heads, birds) }\end{array}$ & $\begin{array}{c}\text { Size per farm } \\
\text { (heads, birds) }\end{array}$ \\
\hline Beef cattle & 94,360 & 2,676 & 28.4 \\
Hanwoo & 89,403 & 2,561 & 28.6 \\
Dairy cattle & 5,498 & 411 & 74.8 \\
Pig & 4,909 & 10,187 & 2,075 \\
Chicken & 3,004 & 164,131 & 54,637 \\
Duck & 722 & 9,772 & 13,833 \\
\hline
\end{tabular}

\section{HISTORY OF HANWOO}

Korean Hanwoo includes four breed types: brown, brindle, black, and Jeju black [2]. Since 5000 years ago, Hanwoo has been a typical breed used for farming, transportation, and religious sacrifice. During several wars, including World War II and the Korean war, the population of Hanwoo shrank to 0.4 million head [1]. However, farmers have gradually repurposed the Hanwoo from draft animals to beef cattle since the 1960s [2]. Recently, the population of Hanwoo has recovered to 2.6 million head.

The origin of Hanwoo (also known as northeast Asian cattle) has been studied with regard to regional pathways of domestication. Some researchers suggested that Hanwoo originated from a cross between zebu and taurine cattle that migrated from Mongolia [3,4]. Another study indicated that Asian cattle 


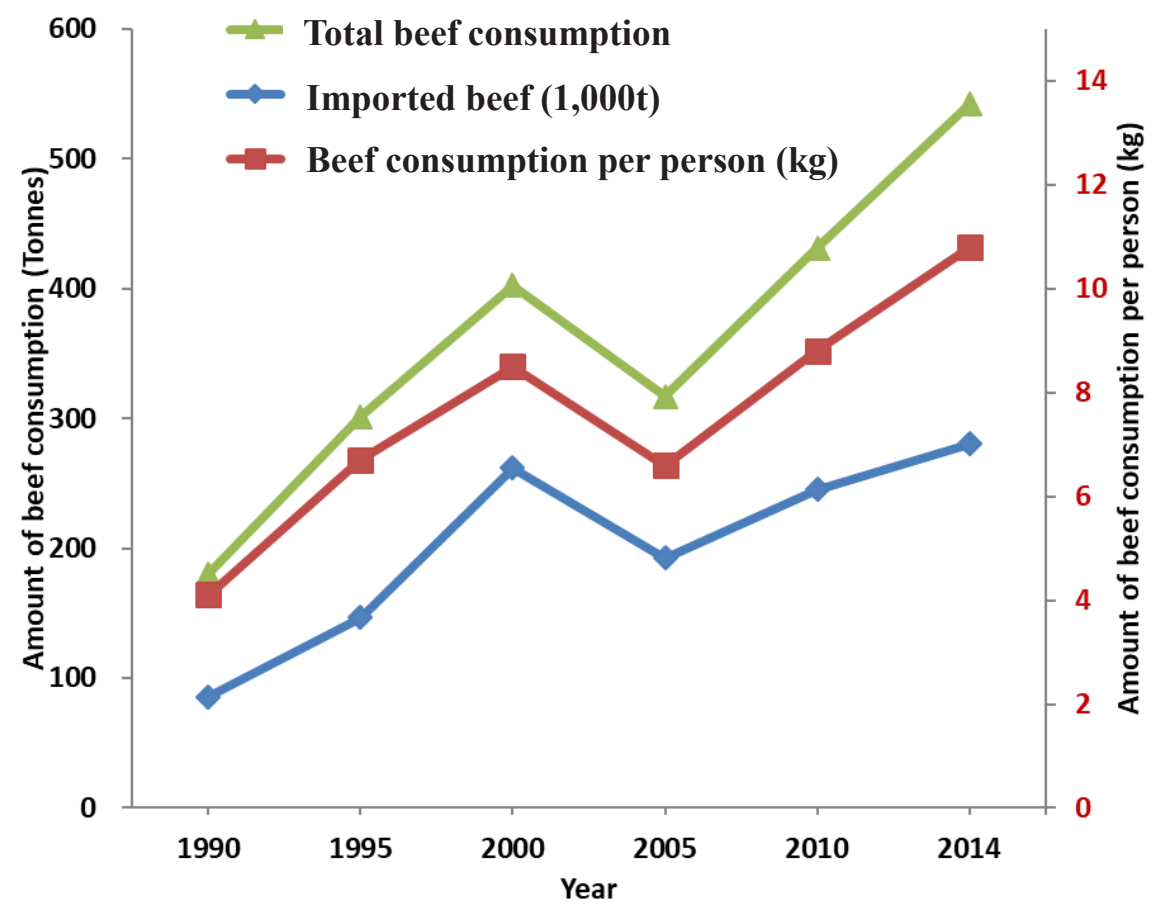

Figure 3. Changes in consumption of beef in South Korea [29].

were of a hybrid taurine-indicine origin [5]. A recent study that analyzed cattle diversity demonstrated differentiation of Asian taurine from Western taurine cattle [2] using 50K SNP chip data to compare neighbouring phylogenetic trees based on principal component analysis. This analysis included African taurine, European taurine, Asian taurine, and zebu cattle. The Hanwoo tree was clearly separated from the European taurine cattle breeds, and the result suggested a northeast cattle breed with isolated domestication [6].

The Research Development Administration (RDA) developed a method for the breeding of superior beef cattle and of feeding for increased productivity of Hanwoo industry. After implementation of the National Hanwoo Breeding System and the use of artificial insemination, the performance and carcass characteristics of Hanwoo cattle dramatically improved. The average carcass weight of Hanwoo steers increased from $343 \mathrm{~kg}$ in 2000 to $437 \mathrm{~kg}$ in 2016. The marbling score also improved from 3.6 in 2000 to 5.6 in 2016 [7]. Over recent decades, Hanwoo as beef cattle have improved not only as a major meat source, but also as a premium agricultural product in the livestock industry. Because of technical advancements in breeding and feeding systems, the performance in terms of quality and quantity of Hanwoo has steadily increased.

\section{HANWOO BREEDING AND PRODUCTION SYSTEMS}

The Hanwoo breeding program is a purebred breeding system that started in 1983 and consists of a performance and progeny test. A performance test is a program of selecting candidate bulls based on their own growth performance (for example, growth traits at 12 month of age) followed by a progeny test using progeny carcass traits for the candidate bulls. The pedigree and phenotypic growth and carcass data from the performance and progeny test have been used to evaluate estimated breeding values (EBVs) using best linear unbiased prediction method, and 20 bulls are selected annually to have their semen distributed across the Hanwoo industry.

The annual genetic gain of Korean Proven Bull (KPN) selection to date from performance and progeny tests in the Hanwoo breeding program has been very successful. For example annual genetic gain for carcass weight was $4.05 \mathrm{~kg}$, eye muscle area $1.58 \mathrm{~cm} 2$, marbling score 0.37 , and back fat thickness (BFT) was 0.05 , respectively [8]. However, there are still some limitations in the Hanwoo breeding system. Firstly, the average generation interval for selection of a proven bull would take at least 5.5 years, the period from birth to selection through performance and progeny tests. Secondly, the number of progeny to be tested in the progeny testing program is relatively small at 7 to 8 progeny for each of bull, hence the accuracy of EBVs is limited to $70 \%$ in this Hanwoo breeding program. Therefore, there is room for improvement of the breeding program by overcoming these systematic limitations using cutting edge technologies, notably, genomic selection methods [9].

Around 3 million Hanwoo cattle are raised annually in Korea, and the number of farm households is currently estimated at 89,493 . Approximately 900,000 Hanwoo are slaughtered each 
year for sale of beef to the market. As shown in Figure 4, the Hanwoo breeding and production system consists of a highly structured pyramid production system comprising three tiers: seed stock sector; multiplier or cow-calf operations; and feedlot sector. The seed stock sector is run by the Korean Government and consists of the Hanwoo breeding program and performance and project testing). Annually, 20 proven bulls (KPN bull) are selected to have their semen distributed across multiplier and feedlot farms (Figure 5). The second tier are full time multipliers or cow-calf operations, which are relatively small in Korea. The majority of these farms would be feedlot farms in which animals are bred and feedlotted at the same time. Most of animals are registered in the pedigree recording system of the Korea Animal Improvement Association (http:// www.aiak.or.kr/) and the Animal Product Traceability System (http://aunit.mtrace.go.kr/) when they are born. Moreover, carcass data for most slaughtered animals are stored in the National Database at the Korea Institute for Animal Products Quality Evaluation (http://www.ekape.or.kr/). The stored data including pedigree and carcass data would be useful for reevaluation of genetic performance of KPN bulls to improve accuracy and cow breeding value estimation for smallholder

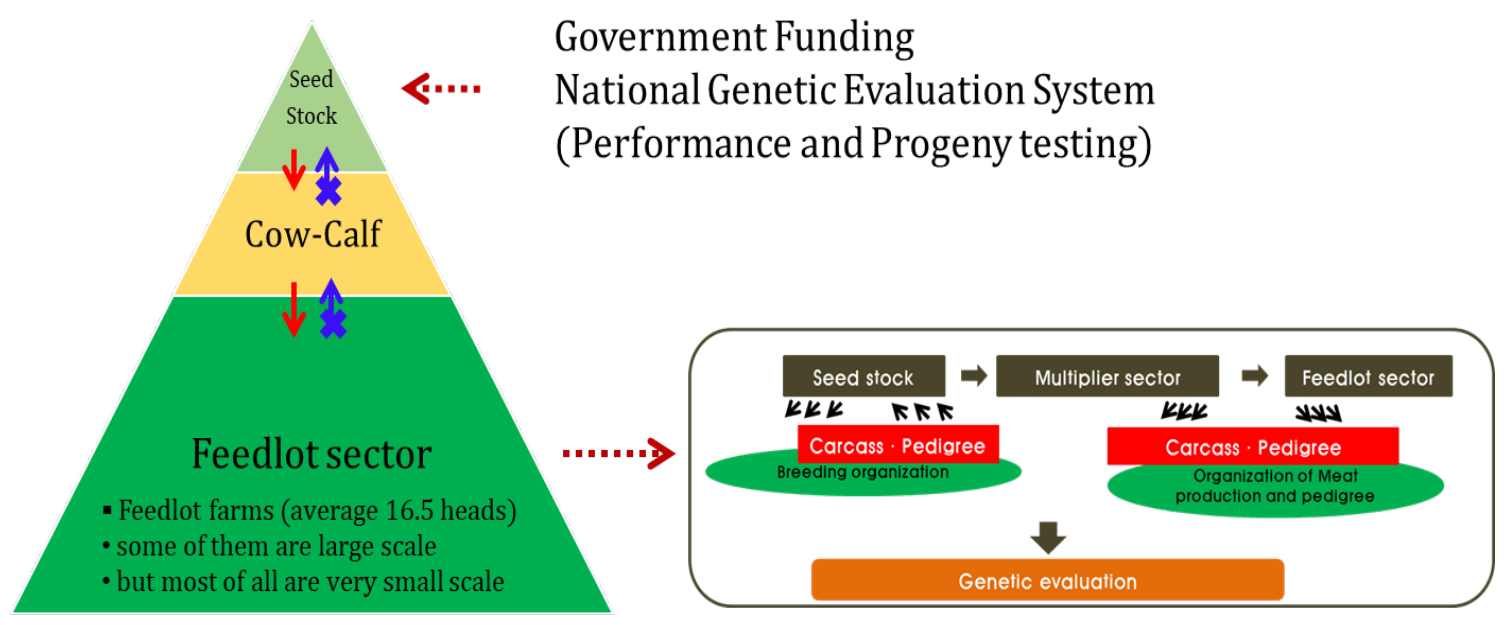

Figure 4. Hanwoo breeding and production systems in Korea [28].

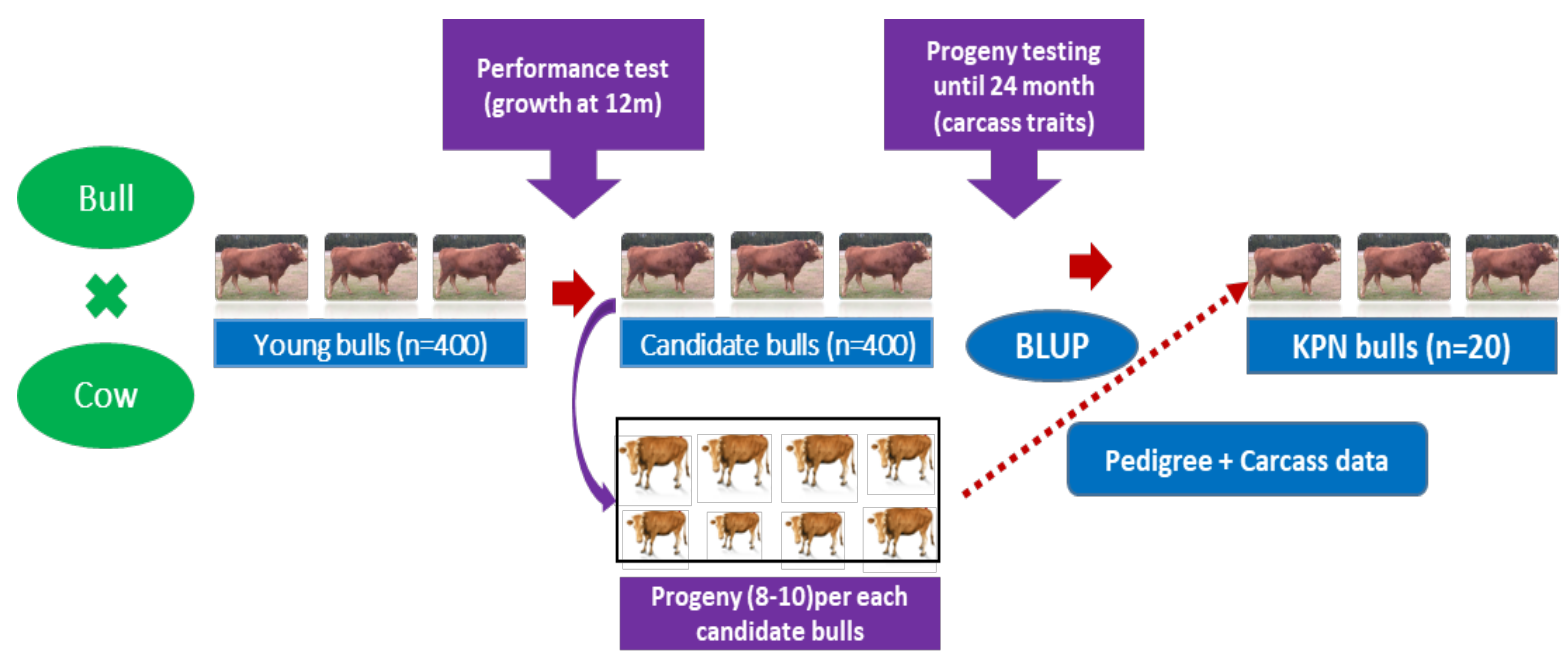

Figure 5. Schematic diagram of performance and progeny testing in the Korean Hanwoo breeding program. 
Hanwoo farms.

\section{BEEF GRADING SYSTEM}

The beef carcass grading system introduced in Korea commenced with the Livestock Industry Act in 1993 [7]. Carcass characteristics such as carcass weight and marbling score of Hanwoo beef have continuously improved over the last two decades (Figures 6,7 ). The rate of castration also steadily increased from 2003 and plateaued in 2013 (Figure 7). The frequency rate of Hanwoo carcass with quality grades above 1 has also annually increased markedly and also plateaued in 2013. Interestingly, both the castration rate and quality grade improvement have been positively correlated. Carcass weight has also improved during the last 10 years. These data indicate that the Hanwoo breeding system works, and has not only improved quality grade but has also increased carcass weight. The meat quality of Hanwoo beef is classified by 5 grades that include $1++, 1+, 1,2$, and 3, depending on the degree of marbling, meat color, fat color, firmness of rib eye and maturity (Figure 8). The grading is performed at loin muscle between the 13th rib and the 1st lumbar vertebra. Meat yield grade in Korea consists of three grades according to the evaluation category and criteria. A, B, and C grades depend on meat yield index values calculated from an equation (Figure 9) which contains the rib eye area, BFT and carcass weight. There are differences between quality grading systems for beef in Korea, Japan and the USA (Figure 10).

In the Hanwoo carcass grading system, the frequency rate of yield grade A decreased from 43\% in 2003 to $26.1 \%$ in 2015 [7], whereas the production rate of high marbled cattle increased (Figure 11). The demand for improved marbling score tends to selectively increase the slaughtering age of Hanwoo cattle. Statistical analyses support this observation, as the av-

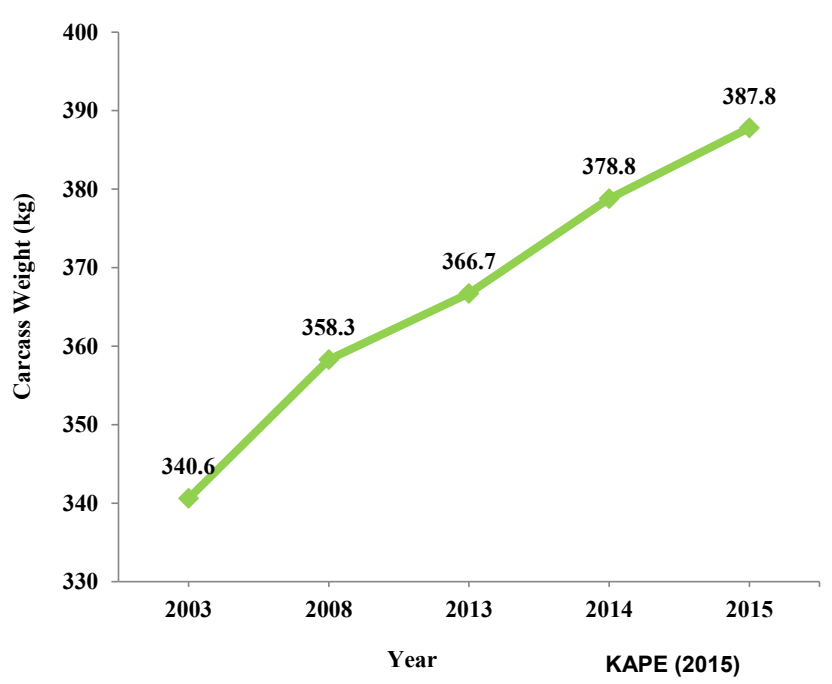

Figure 6. Changes in average Hanwoo carcass weights $(\mathrm{kg})$ in South Korea [7]. erage slaughtering age of a Hanwoo steer has shifted from 30.2 months in 2009 to 32.5 months in 2014 [7]. Extended fattening periods increase production costs and decrease the rate of yield grade A which are major issues in the Hanwoo industry that remain to be resolved. Recently, the National Institute of Animal Science demonstrated some solution options, which included feed additives and curtailed feeding periods with a precise genetic management system.

\section{BEEF TRACEABILITY SYSTEM}

A traceability system for all Hanwoo beef was applied by the Ministry of Agriculture, Food, and Rural Affairs of Korea since 2008. This system ensures that tracking information on Hanwoo beef from farm to table is available to the consumer. Through this system, consumers can verify cattle's identity and purchase beef with confidence because it assures transparency of beef distribution when the cattle on the market are identical. An individual 12-digit identification number is generated for every Hanwoo calf at birth with DNA identity testing to prevent false labeling of origin [7]. This system is to assure consumers of the safety of meat by a prompt identification system if any safety issues occur and enable consumers to record or manage all the information in every step from farm to table. Moreover, accumulation of Hanwoo genetic or carcass information generates a large amount of data which enables not only determining individual ability but also management of precision livestock farming.

\section{MEAT CHARACTERISTICS OF HANWOO}

Previous reports compared the characteristics of Hanwoo beef to other breeds [10-12]. According to a study comparing

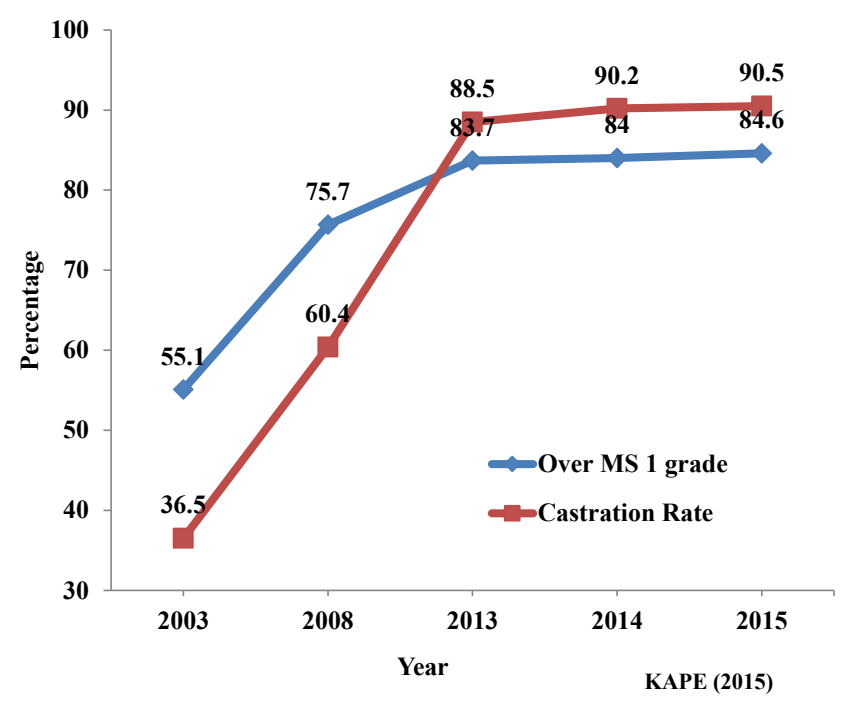

Figure 7. Changes in percentage of Hanwoo cattle with marbling score (MS) over grade 1 and Hanwoo castration rates in South Korea [7]. 

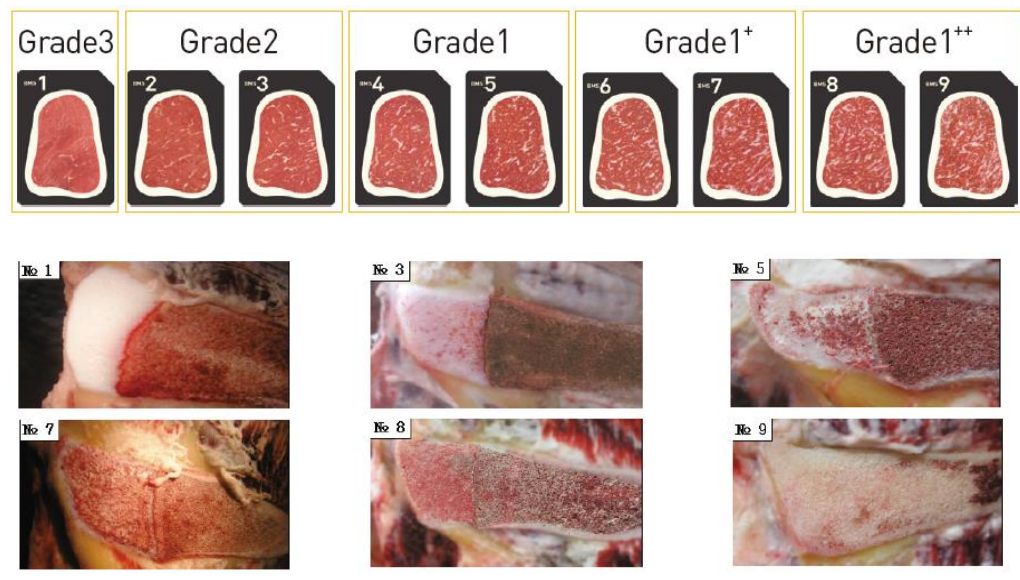

\section{Marbling \\ - Preliminary quality grading is decided with the degree of marbling}

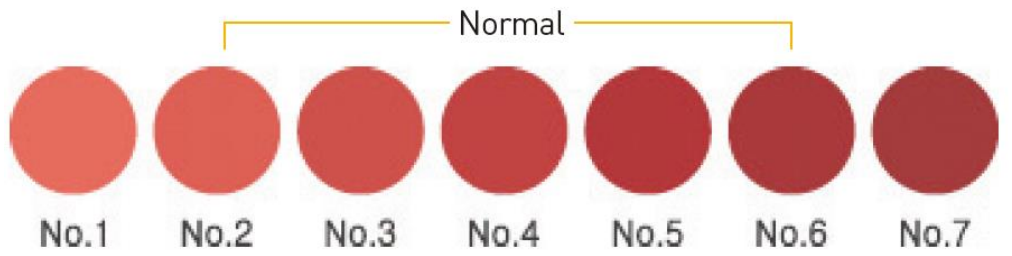

\section{Meat Color}

- Meat color of the cut surface of ribeye is determined in accordance with meat color

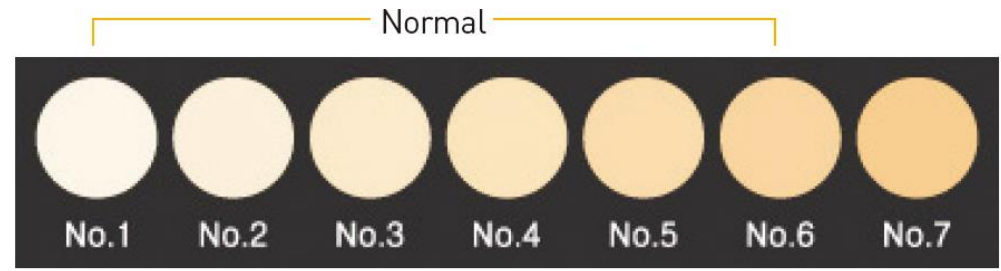

\section{Fat color}

Fat color of the cut surface for intra-muscle and backin accordance with fat color
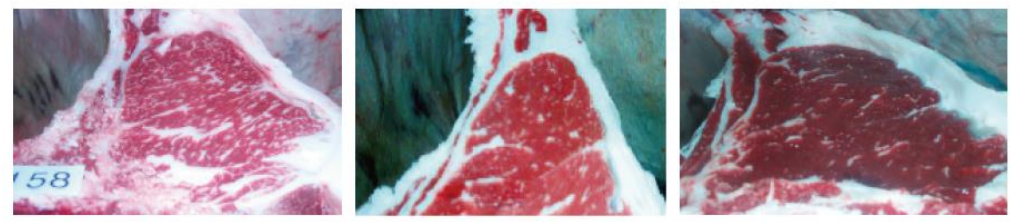

\section{Texture}

- The fine muscle and firm texture of the cut surface is determined.

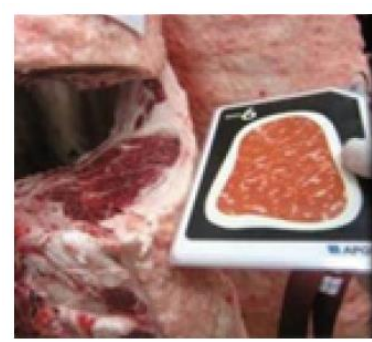

<Marbling >

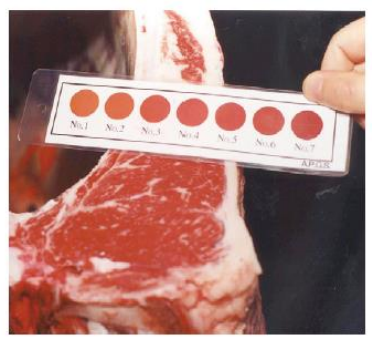

<Marblingcolor>

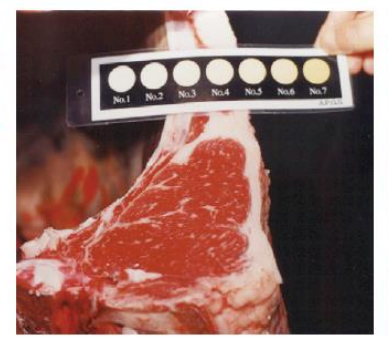

$<$ Fat color >

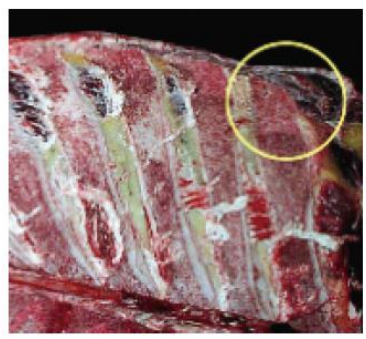

$<$ Maturity $>$

Figure 8. Beef quality grading system in South Korea $[26,27]$.

the longissmus dorsi of 24-month-old Angus and Hanwoo, the percentage of intramuscular fat (IMF) was two-fold greater in Hanwoo, but BFT was two-fold greater in Angus cattle [11]. Previous studies also noted that BFT was low in not only Hanwoo, but also Wagyu steers compared to the Angus breed [13]. A prior study indicated that Angus BFT is consistently higher than Wagyu under similar diet conditions $[13,14]$.
These findings support both Wagyu and Hanwoo having genetic potential for reduced BFT under high fattening diets. The marbling score for Hanwoo beef is presented as $1^{++}, 1^{+}, 1,2$, and 3 in the Korean quality grade system. A longissimus dorsi (LD) with a $1^{++}$grade represents $21.5 \%$ IMF content and a 2 grade represents only 6.6\% IMF content [12]. Figure 11 shows the quality grade differences among countries depending on 

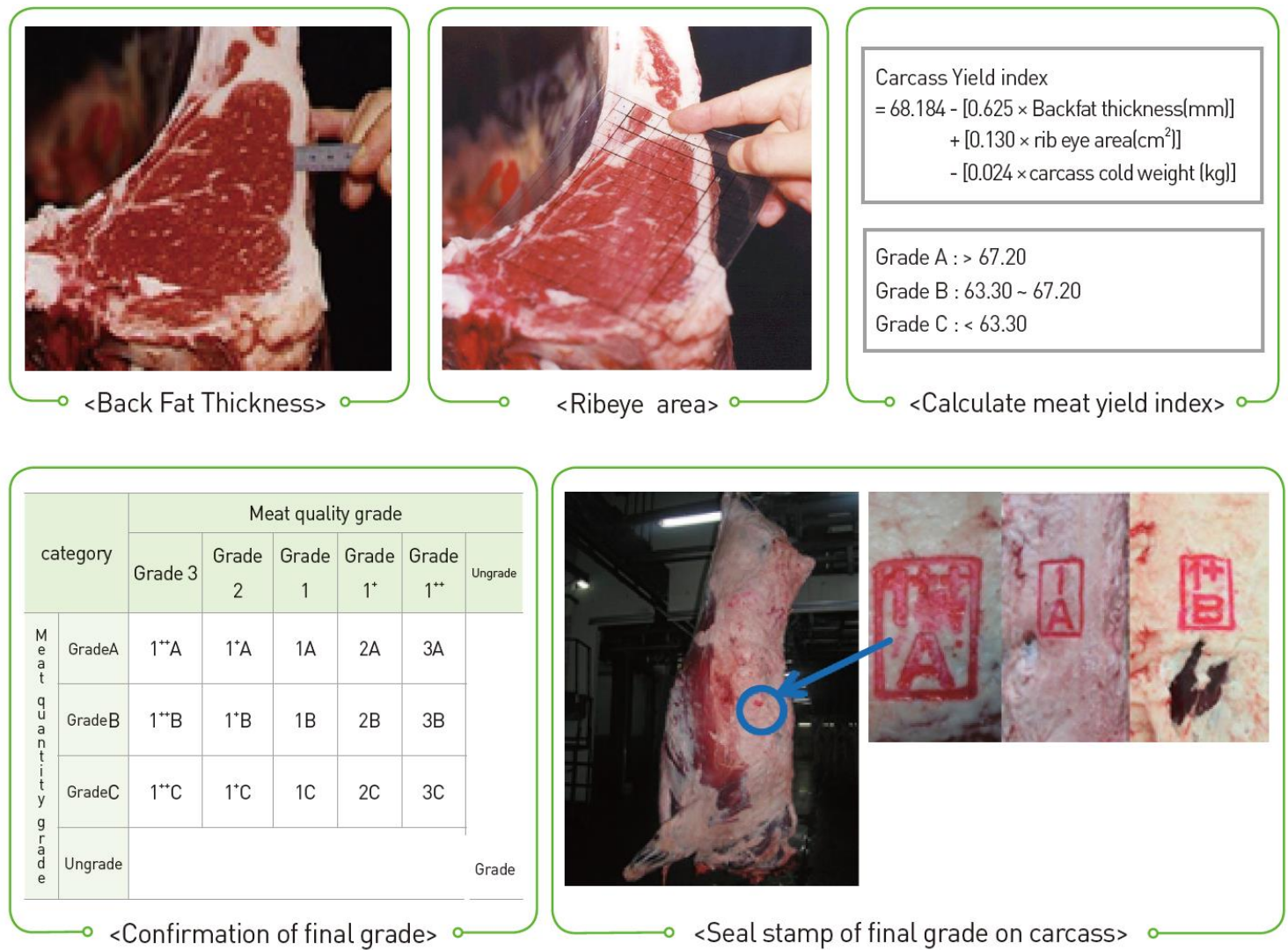

Figure 9. Yield grade, meat quality grade and final grade system in South Korea $[22,26]$.

crude fat percentage of LD muscle [7]. The fat percentage associated with grades varies significantly depending on consumer requirements, and both Japan and Korea have different marbling score systems compared to the USA.

The fatty acid composition of Hanwoo and Angus LD muscle varies [11]. Angus beef displays more n-3 polyunsaturated fatty acids (PUFAs) such as linolenic acid (C18:3 n-3) in IMF fat, while Hanwoo beef exhibit greater n-6 PUFAs, such as linoleic acid (C18:2 n-6), in IMF fat. The ratio of n-6/n-3 PUFAs is determined by diet and feeding duration [15]. A high grain diet may increase $n-6$ fatty acid by more in Hanwoo beef compared to Angus beef [11]. This research also showed that the percentage of oleic acid (C18:1 n-9) was greater in Hanwoo compared to Angus beef. Wagyu and Hanwoo fat has high oleic acid content with a low melting point and high softness compared to lower oleic acid content beef of other breeds. The composition of fatty acids in beef has also been shown to affect palatability [11]. Recently, some study found that Hanwoo beef contained high glutamic acid compared to other breeds and this result supported characteristics of Hanwoo beef [10]. There is a study that indicated beef containing oleic acid induced human high density lipoprotein (HDL) cholesterol but did not affect low density lipoprotein (LDL) cholesterol contents [16]. Previous research data demonstrated that the beef

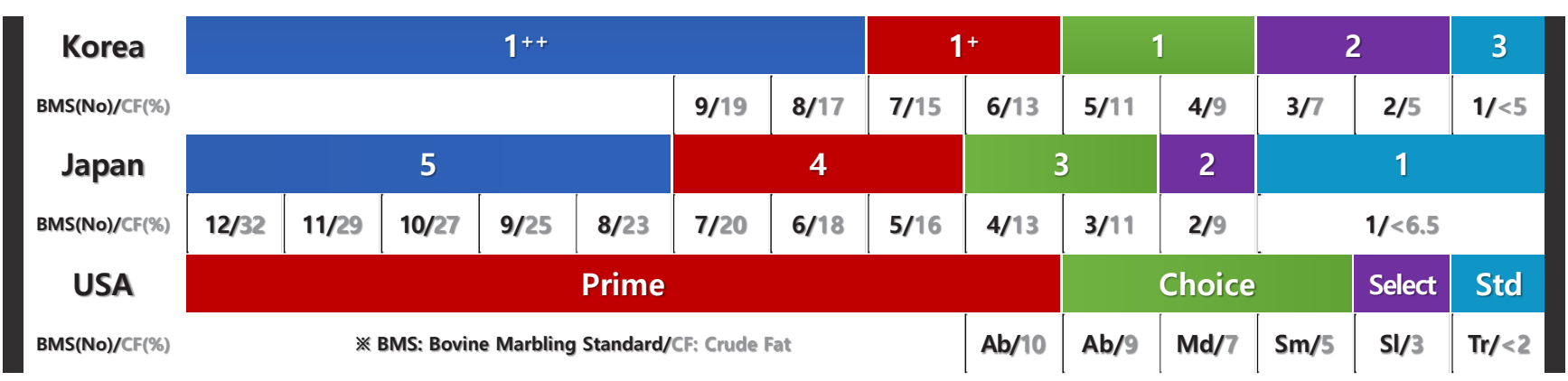

Figure 10. Comparison of beef quality grading scores and marbling standards (BMS) between South Korea, Japan and USA, based on the crude fat percentage (CF \%) in the longissimus dorsi muscle [7]. 


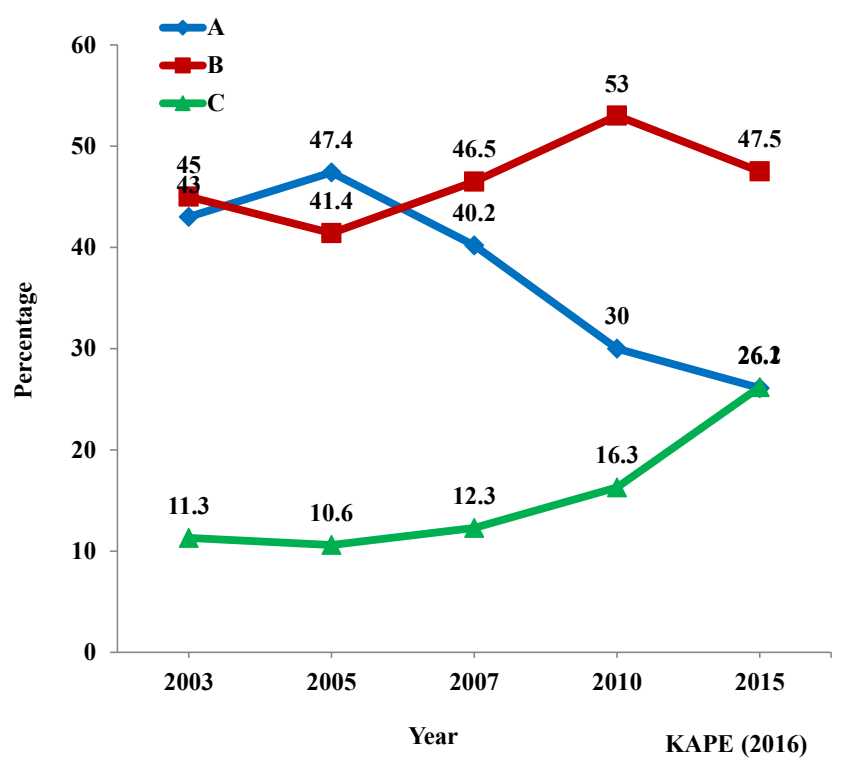

Figure 11. Changes in percentage of Hanwoo cattle with yield grades A, B, and C in South Korea [7].

containing high oleic acid not only increased palatability of meat but also supported functionally healthly food for humans.

\section{FEEDING SYSTEM FOR HANWOO}

Although carcass characteristics of beef cattle are affected by the genetic potential of different breed types, environmental factors such as diet and harvest time are also important factors determining beef quality and quantity [17]. Moreover, the fattening program for marbled beef is determined by energy content of the diet, breed, and feeding duration $[13,18]$. The Hanwoo feeding program in Korea stipulates a restricted concentrate (total digestible nutrient (TDN) 69\%, crude protein (CP)) $14 \%$ and ad libitum pasture or rice straw. The fattening period has been divided into three periods: the growing stage (6 to 11 months), the early fattening period (12 to 20 months), and the final fattening period (21 to 29 months) [19]. During the early fattening periods, Hanwoo cattle are fed a concentrate (TDN 71\%, CP 13\%) and ad libitum rice straw, then a slightly different concentrate (TDN 73\%, CP 11\%) with ad libitum rice straw. During the finishing stage, $90 \%$ concentrate and $10 \%$ rice straw is provided to maximize IMF development [10].

A prior study using US or Canadian beef cattle suggested that extension of the feeding period affects the meat quality of beef $[20,21]$. However, extension of feeding periods increases BFT or inedible fat and can ultimately have a negative impact on beef grade and yield. A previous report indicated that a 29-month-old endpoint is a suitable economic feeding period for Hanwoo [22]

A study that compared carcass characteristics between energy diets and endpoints of Hanwoo steers [23] found that marbling score and carcass weight steadily increased to endpoints of 26, 28, and 30 months. High TDN based diet increased marbling scores at 28- and 30-months of age. These data consistently show that Wagyu and Hanwoo BFT was relatively lower than those of Angus [15,23].

To produce beef that meets consumer requirements in the Korean market, castration of cattle is advantageous with regard to IMF development. A previous study showed that early castration increased marbling score but reduced yield grade, while late castration reduced marbling score but increased yield grade [24]. This study suggested that 6 months was the best age for castration of Hanwoo cattle. Recently, Korean consumer demand has increased for a fine marbling. This phenomenon will require alterations in the quality grading and feeding systems. Although few studies on effects on fineness of marbling are available, some suggest that early castration or a high-energy diet regulates marbling scores [15,24]. Moreover, age of castration or time of weaning may affect fineness of marbling fat in beef cattle.

Hanwoo cattle typically receive a high-energy diet from 6 to 29 months of age, including individual cattle with differing genetic potential for marbling. Although there have been attempts to predict individual marbling potential using EBVs, few studies have evaluated the interaction of EBV and castration age, feeding program, and duration of feeding. According to a recent study of Hanwoo, serum components such as glucose and triglyceride levels are associated with marbling EBV and thus influence marbling score [25]. These findings indicate that the level of marbling is greater in high-EBV groups, but diet had no effect. They also suggest synergistic potential for genetic-based management using both genetic selection and precision, targeted feeding systems for the Hanwoo industry.

\section{PROSPECT OF BEEF PRODUCTION IN SOUTH KOREA}

Although consumption of local beef has increased, there has also been a steadily increasing amount of imported beef over several decades (Figure 3). Average feeding cost of Hanwoo also increased from 2,170,000 won/head (2010) to 2,982,00 won/head (2016). To increase marble score, many of Hanwoo farmers tend to extend the feeding period of Hanwoo. Moreover, consumer demands are moving from coarse marbling (marbling quantity) to fine marbling (marbling quality) of Hanwoo beef. Therefore, Hanwoo producers need to not only reducing feeding cost also increase fine marbling score. There is several possible ways to reduce feeding cost but also to increase meat quality. Local pasture source, Italian ryegrass or corn silage, has been planted in the southern area of South Korea. These pastures help to reduce feeding cost especially 
as pasture or pasture mixed with total mixed ration (TMR) feeds. Local TMR companies help to spread efficient feeding technology in local farms. To increase yield grade, there is growth enhancing technology to help improve yield grade at final fattening periods [30]. Especially, these techniques enable dose titration of treatment to increase ribeye area and reduced BFT of Hanwoo steers.

Recently, to reduce feeding cost or induce feed efficiency, it is necessary to determine individual genetic characteristics and provide precision management based on individual characteristics. Korean traceability system has provided sustainable carcass data to a national based research institute. This livestock big data may help to increase accuracy of Hanwoo precision management. There are several ongoing national projects that have been processed at the National Institute of Animal Science.

\section{CONCLUSION}

This review has discussed current issues and the future of beef production in Korea, mainly focusing on the history, industry characteristics, and the production of beef from Hanwoo, which represent almost $90 \%$ of Korean beef cattle. Although there have been many changes in the Hanwoo industry, Hanwoo cattle still offer the best source of beef for Korean consumers. In comparison with other agriculture-based economies, the number of Hanwoo farmers has dramatically decreased in recent decades and large-scale feedlot systems have become more common. This situation requires younger and smarter farmers to meet the continuing challenges faced by the Hanwoo industry including imported feed costs, increasing calf prices, increasing land costs, and cheap imported beef. Many technologies are available to those raising Hanwoo cattle. However, technologies with a dual purpose benefit, such as genetic-based precision management, are still required.

\section{CONFLICT OF INTEREST}

We certify that there is no conflict of interest with any financial organization regarding the material discussed in the manuscript.

\section{ACKNOWLEDGMENTS}

Development of this review was supported by the "Cooperative Research Program for Agriculture Science \& Technology Development (Project No. PJ01091002)" Rural Development Administration, Republic of Korea.

\section{REFERENCES}

1. Korean Statistical Information Service (KOSIS). Farm house- holds by size of raising Korean beef cattle/total head [Internet]. Daejeon, Korea: Korean Statistical Information Service; 2017 [cited 2018 Jan 18]. Available from: http://kostat.go.kr/portal/ korea/kor_nw/2/1/index.board?bmode=read\&bSeq=\&aSeq $=365979$ \&pageNo $=1$ \&rowNum $=10 \&$ navCount $=10 \&$ currP $\mathrm{g}=\& s$ Target $=$ title\&sTxt $=$

2. Lee SH, Park BH, Sharma A, et al. Hanwoo cattle: origin, domestication, breeding strategies and genomic selection. J Anim Sci Technol (Kor) 2014;56:2.

3. Han SW. The breed of cattles. Seoul, Korea: Sun-Jin publishing; 1996. p. 148-60.

4. Yoon DH, Park EW, Lee SH, et al. Assessment of genetic diversity and relationships between Korean cattle and other cattle breeds by microsatellite loci. J Anim Sci Technol (Kor) 2005;47:341-54.

5. McTavish EJ, Decker JE, Schnabel RD, Taylor JF, Hillis DM. New world cattle show ancestry from multiple independent domestication events. Proc Natl Acad Sci USA 2013;110:E1398406.

6. Mannen H, Kohno M, Nagata Y, et al. Independent mitochondrial origin and historical genetic differentiation in North Eastern Asian cattle. Mol Phylogenet Evol 2004;32:539-44.

7. Korean Instititue for Animal Products Quality Evaluation [Internet]. Sejong, Korea: KAPE: Annual Report for Animal Products Research. (Kor); 2016 [cited 2016 Mar 7]. Available from: http://www.ekapepia.com/home/homeIndex.do

8. Park B, Choi T, Kim S, Oh SH. National genetic evaluation (system) of Hanwoo (Korean native cattle). Asian-Australas J Anim Sci 2013;26:151-6.

9. Meuwissen TH, Hayes BJ, Goddard ME. Prediction of total genetic value using genome-wide dense marker maps. Genetics 2001;157:1819-29.

10. Jo C, Cho SH, Chang J, Nam KC. Keys to production and processing of Hanwoo beef: a perspective of tradition and science. Anim Front 2012;2:32-8.

11. Cho SH, Park BY, Kim JH, et al. Fatty acid profiles and sensory properties of Lonsissimus dorsi, Triceps brachii, and Semimembranosus muscles from Korean Hanwoo and Australian Angus beef. Asian-Australas J Anim Sci 2005;18:1786-93.

12. Cho SH, Kim J, Park BY, et al. Assessment of meat quality properties and development of a palatability prediction model for Korean Hanwoo steer beef. Meat Sci 2010;86:236-42.

13. Chung KY, Lunt DK, Choi CB, et al. Lipid characteristics of subcutaneous adipose tissue and M. lomgissimus thoracis of Angus and Wagyu steers fed to US and Japanes endpoints. Meat Sci 2006;73:432-41.

14. Greenwood PL, Siddell J, Walmsley BJ, et al. Post-weaning substitution of grazed forage with a high-energy concentrate has variable long-term effects on subcutaneous fat depths and marbling in Bos taurus genotypes. J Anim Sci 2015;93: 4132-43.

15. Chung KY, Lunt DK, Kawachi H, Yano H, Smith SB. Lipo- 
genesis and stearoyl-CoA desaturase gene expression and enzyme activity in adipose tissue of short- and long-fed Angus and Wagyu steers fed corn- or hay-based diets. J Anim Sci 2007;85:380-7.

16. Gilmore LA, Crouse SF, Carbuhn A, et al. Exercise attenuates the increase in plasma monounsaturated fatty acids and highdensity lipoprotein but not high-density lipoprotein $2 \mathrm{~b}$ cholesterol caused by high-oleic ground beef in women. Nutr Res 2013;33:1003-11.

17. Crouse JD, Cundiff RM, Koch M, Koohmaraie T, Seideman SC. Comparisons of Bos indicus and Bos taurus in heritance for carcass beef characteristics and meat palatability. J Anim Sci 1989;67:2661-8.

18. Kim KH, Lee JH, Oh YG, et al. The optional TDN levels of concentrates and slaughter age in Hanwoo steers. J Anim Sci Technol (Kor) 2005;47:731-44.

19. Lim DH, Han HK, Kim JH, et al. Annual report for livestock animal research. Suwon, Korea: National Institute of Animal Science; 2013. Report No.: 11-1390906-000217-10.

20. Dolezal HG, Smith GC, Savell JW, Carpenter ZL. Effect of time on feed on the palatability of rib steak from steers and heifer. J Food Sci 1982;47:368-73.

21. Zinn DW, Gaskins CT, Gann GL, Hedrick HB. Beef muscle tenderness and influenced by days of feed, sex, maturity and anatomical location. J Anim Sci 1970;31:307-18.

22. Ministry for Food, Agriculture, Forestry, and Fisheries (MFAFF). Processing standard for meat products act, Grading, fabri- cation and cutting of beef carcass. Seoul, Korea: Ministry for Food, Agriculture, Forest and Fisheries; 2007. p. 82.

23. Chung KY, Chang SS, Lee EM, et al. Effects of high energy diet on growth performance, carcass characteristics, and blood constituents of final fattening Hanwoo steers. CNU J Agric Sci (Kor) 2015;42:261-8.

24. Hong SK, Baek BH, Kang SH, Cho WM. Effects of restricted feeding and market weights on the carcass characteristics of Hanwoo steers. Korean J Anim Sci 1996;38:215-30.

25. Chung KY, Lee SH, Chang SS, et al. Effects of high energy diet on growth performance, carcass characteristics, and blood constituents of Hanwoo steers distributed by estimated breeding value for meat quality. CNU J Agric Sci (Kor) 2015;42: 361-8.

26. National Institute of Animal Science (NIAS). Meat buyers guide for Hanwoo beef. Suwon, Korea: National Institute of Animal Science (NIAS); 2016.

27. National Livestock Cooperatives Federation (NLCF). Korean carcass grading standard. Seoul, Korea: National Livestock Cooperatives Federation; 1998.

28. Lee SH, Kim UH, Dang CG, et al. Strategies to multiply elite cow in Hanwoo small farm. J Embryo Transf 2013;28:79-85.

29. Kang DH, Ki KS, Jang SS, et al. Effect of potato byproduct on growth performance, blood metabolites, and carcass characteristic of Hanwoo steers. CNU J Agric Sci (Kor) 2017;44: 574-85. 